\title{
Joseph Morsel
}

\section{CpenEdition \\ Journals}

Édition électronique

URL : http://journals.openedition.org/ifha/1147

DOI : 10.4000/ifha. 1147

ISSN : 2198-8943

\section{Éditeur}

IFRA - Institut franco-allemand (sciences historiques et sociales)

\section{Référence électronique}

Joseph Morsel, «», Revue de l'IFHA [En ligne], Date de recension, mis en ligne le 01 janvier 2002,

consulté le 22 septembre 2020. URL : http://journals.openedition.org/ifha/1147 ; DOI : https://doi.org/ 10.4000/ifha. 1147

Ce document a été généré automatiquement le 22 septembre 2020.

(C)IFHA 
Joseph Morsel

" Observer, mesurer, dessiner et décrire ": telles sont les tâches que s'assigne la historische Bauforschung, histoire de la construction qui se distingue de sa cousine l'architecture (en tant que discipline) en ce que celle-là part de l'objet construit qu'elle étudie rétrospectivement alors que celle-ci a une démarche prospective. C'est en cela que, paradoxalement, elle considère « le bâtiment en tant que source » alors qu'il s'agit en premier lieu d'un résultat. L'intérêt de l'étude des objets construits n'échappera à personne : comme tout processus de production, la construction renvoie au mode d'organisation sociale de la société considérée. Mais cela va encore plus loin dans le cas de la construction : elle est très étroitement liée aux représentations sociales (cf. par exemple la métaphore de «l'édifice social » et plus spécifiquement, à propos du Moyen Âge, la polysémie soigneusement entretenue du terme ecclesia). En outre, la construction est une des dimensions du processus de spatialisation par lequel tout système social produit son espace propre. Enfin, en tant qu'activité qui exige souvent la mobilisation d'énergies humaines et de moyens matériels considérables, la construction a fréquemment eu un effet « socialisant » important, non seulement par le regroupement des personnes qu'elle induit mais aussi par la forme organisée que prend ce regroupement : on ne manque pas de cas d'organisation collective née à l'occasion de grands travaux à réaliser, en particulier les murailles.

2 Mais comme le montre l'énumération des tâches qui lui sont reconnues dans ce volume (destiné à honorer l'un des principaux représentants de la discipline, Walter Haas), la historische Bauforschung paraît renoncer à cette dimension sociale globale au profit d'une approche « interne ». D'ailleurs, l'une des contributions de ce numéro spécial de la revue architectura (daté de 1994 mais paru en 1995), celle de T. BREUER, opte radicalement pour une définition étroite, par rapport aux disciplines voisines (histoire de l'art, architecture, conservation de patrimoine) au lieu d'insister sur les apports spécifiques de cette approche à la connaissance globale. Ainsi, ce dont le bâtiment est censé être la source, c'est la reconstitution de sa genèse propre, et non le système social qui lui a donné naissance - les discours contemporains sur le bâtiment en question constituant dans le meilleur des cas le référent social, sans tenir compte des effets de distanciation et de brouillage qui existent entre logique sociale et discours. Quoique la plupart des contributions traitent du Moyen Âge, certaines concernent les époques moderne ou contemporaine. La plupart d'entre elles s'attachent à des bâtiments 
particuliers : le mémorial du Deutsches Eck à Coblence et les débats autour de sa restauration récente ; les maisons médiévales de Naumburg ; le dortoir du monastère de Maulbronn ; les bibliothèques des monastères bénédictins de l'espace alémanique au XVIIIe s. ; l'articulation nef-transept de la basilique d'Eginhard à Seligenstadt (restituée à partir du plan de Saint-Gall) ; les bâtiments médiévaux en Saxe, et notamment la cathédrale de Meißen en cours de restauration; le clocher fortifié de Solnhofen, datant du XIe s. ; le palais de l'évêque de Trèves Nicetius (localisé et restitué à partir du poème de Venance Fortunat) ; un gros dossier sur le célèbre château de Castel del Monte ; la confessio (tombeau du martyr) sous le maître-autel de la cathédrale de Ratisbonne, inspirée de celle de Saint-Pierre de Rome ; les tours dans la ville de Ratisbonne ; le pont de Ratisbonne ; le campanile de Sienne ; la rotonde de Honcourt ; le chœur occidental de la cathédrale de Naumburg. D'autres contributions s'intéressent plutôt à des modes de construction particuliers : l'adoption en Allemagne du Nord de la brique comme matériau de construction (aujourd'hui considéré comme « naturel » dans la région) à la place du granit taillé et le remplacement massif de celui-ci par celle-là ; la combinaison rare de collatéraux perpendiculaires voûtés en berceau et de voûtes d'ogives nervées dans la nef ; l'évacuation des eaux pluviales dans les grandes églises médiévales; les spolies antiques utilisées dans l'église byzantine de Saint-Mamas à Naxos ; le système numérique employé (à défaut de tout recours à la géométrie) pour construire la chapelle palatine d'Aix-la-Chapelle. D'innombrables plans et photographies contribuent à la richesse de cet ouvrage, qui donne au final l'impression plutôt d'un recueil de sources commentées, et non d'un ouvrage d'histoire. 